\title{
Interplay between Inflammation, Coagulation And Redox Status in Early Onset Neonatal Sepsis: Insight into Prediction, Diagnosis and Management
}

\author{
Nema A. Soliman ${ }^{1 *}$, Mohamed S. El Farargy ${ }^{2}$ and Wesam H. Amer ${ }^{3}$ \\ ${ }^{1}$ Department of Medical Biochemistry, ${ }^{2}$ Department of Pediatrics, ${ }^{3}$ Department of \\ Microbiology, Faculty of Medicine, Tanta University, Tanta, Egypt \\ *Corresponding author
}

Keywords

Neonatal sepsis, High mobility group box 1 ,

Thrombomodulin, Heat

shock protein 72 , Redox status

Article Info

Accepted:

10 February 2018

Available Online:

10 March 2018

\section{A B S T R A C T}

Sepsis in newborn infants has a high risk of morbidity and mortality. Despite advances in medicine, diagnosis of neonatal sepsis remains as a major challenge. The aim of this study is to unravel the role played by new network of biomarkers namely high mobility group box 1(HMGB1), thrombomodulin and heat shock protein (Hsp) 72 in addition to redox status in diagnosis of early onset neonatal sepsis before and after antibiotic therapy. The study enrolled 45 neonates, 30 of them had early onset sepsis (group 1), and 15 healthy neonates as a control group (group 2). Neonates with early onset sepsis were classified according to their culture status into culture-proven sepsis $(\mathrm{n}=19)$ (group 1a) and culture negative sepsis ( $\mathrm{n}=11$ ) (group 1b). Levels of HMGB1, thrombomodulin, Hsp72, nitric oxide (NO) and hydrogen peroxide $\left(\mathrm{H}_{2} \mathrm{O}_{2}\right)$ were estimated. Studied biomarkers were investigated before and 5 days after antibiotic therapy. Serum levels of HMGB1, NO and $\mathrm{H}_{2} \mathrm{O}_{2}$ were significantly $(\mathrm{p}<0.05)$ higher in neonates with sepsis than in healthy neonates ( $65.7 \pm 8.7$ vs $38.2 \pm 9.9 ; 33.4 \pm 9.1$ vs $13.6 \pm 1.8$ and $59.6 \pm 7.9$ vs $35.0 \pm 3.4$ respectively) and in culture proven than culture negative neonates $(70.4 \pm 6.4$ vs $57.5 \pm 5.6 ; 36.4 \pm 8.8$ vs $28.1 \pm 7.3$ and $61.3 \pm 7.4$ vs $55.3 \pm 7.0$ respectively) before antibiotic therapy while thrombomodulin and Hsp72 were significantly $(\mathrm{p}<0.05)$ lower in neonates with sepsis than in healthy neonates $(72.3 \pm 11.2$ vs $144.2 \pm 15.6$ and $14.6 \pm 1.6$ vs $32.6 \pm 4.3$ respectively) and in culture proven than culture negative neonates for thrombomodulin $(67.8 \pm 10.7$ vs $80.1 \pm$ 7.4) and non-significance for Hsp 72 showed $p>0.05$ (14.6 \pm 1.5 vs $14.6 \pm 1.9$ ) before antibiotic therapy. Results of all the aforementioned biomarkers improved after antibiotic treatment in sepsis group. HMGB1, thrombomodulin and Hsp72 are considered promising biomarkers for early diagnosis of early onset neonatal sepsis.

\section{Introduction}

Neonatal sepsis is a serious problem associated with high degree of morbidity and mortality in both term and preterm infants (Camacho-Gonzalez et al., 2013). Beyond being a life-threatening condition, sepsis can significantly impair neuron-developmental outcome and can progress rapidly to septic shock and multiple organ dysfunction syndrome, early diagnosis is crucial to improve survival (Klinger et al., 2010). Unfortunately, the diagnosis of sepsis may be difficult in the neonate. The earliest signs of the disease are often subtle and nonspecific, and can be easily confused with 
signs of non-infectious diseases (Palazzi et al., 2006). Blood culture is the gold standard for the diagnosis of sepsis, but at least 48-72 hours are needed for the results and the number of false negative results is not negligible, particularly in early-onset sepsis, for which the blood culture sensitivity is reported to be less than $10 \%$ (Hofer et al., 2012). During sepsis, innate immune cells recognize pathogen-associated molecular patterns such, lipopolysaccharide (LPS), bacterial peptidoglycan and enterotoxins, or damage-associated molecular pattern, such as, heat shock proteins, uric acid, annexins, interleukin (IL)-1 $\beta$, and high mobility group box 1 (HMGB1) (Pisetsky et al., 2011). HMGB1 can actively affect the immune functions of inflammatory cells, once released, HMGB1 can bind to cell-surface receptors and mediate various cellular responses including chemotactic cell movement and release of pro-inflammatory cytokines (e.g., tumor necrosis factor alpha $(\mathrm{TNF}-\alpha)$ and IL-1 $\beta$ ), taken together, these observations characterized HMGB1 as a nonclassical, pro-inflammatory cytokine (Huang et al., 2012).

Inflammation and coagulation have a big participation in sepsis pathogenesis that makes them promising sepsis treatment targets. Thrombomodulin is an endogenous anticoagulant that helps in the maintenance of the anti-inflammatory and anticoagulant state of endothelial system (Okamoto et al., 2016).

Heat shock proteins (Hsps) are proteins that play an important role in stressful conditions including infection (Evans et al., 2010). The human Hsps family consists of at least 12 members, the best known members are the heat inducible form $\mathrm{Hsp} 72$, during time of infection, inducible Hsp72 is found extracellular to facilitate immunological defense responses (Evans et al., 2010). Oxidative stress is defined as an imbalance between the production of reactive oxygen species (ROS) and antioxidant defenses; mild oxidative stress has been demonstrated to promote cell survival, whereas severe oxidative stress has been demonstrated to cause oxidative injury and even death, additionally, sepsis promotes the unbalanced production of oxidant and antioxidant substances (Saugstad et al., 2005).

This study was designed to highlight the role of HMGB1, thrombomodulin, Hsp72 and redox status as an intricate network for sepsis pathogenesis, diagnosis and treatment response in neonates.

\section{Materials and Methods}

This case control study was conducted in Medical Biochemistry, Pediatrics, and Medical Microbiology Departments, Tanta University, Tanta, Egypt and was approved by the ethical committees of the University. Informed consents were obtained from parents to participate in this study.

\section{Patients}

This study was performed on 30 (16 males and 14 females) newborns who were hospitalized at the neonatal intensive care unit at Tanta University Hospital for early onset neonatal sepsis (during the first 72 hours) (group 1). In the sepsis group $(n=30), 19$ infants had positive blood cultures and 11 infants had only clinical signs of sepsis with negative blood culture. A group of healthy matched controls (group 2, n=15) (9 males and 6 females) were enrolled for comparisons of biochemical assays and were selected from the well-baby outpatient clinic.

Infants were enrolled in this study if: a) their postnatal age was 60 breaths/min), chest retraction, cyanosis, respiratory distressbradycardia (heart rate 180/min), poor skin color, capillary refilling time > 3 seconds, 
hypotonia, irritability, lethargy, and seizures. Historical factors associated with increased risk for infections included premature rupture of the membranes (in term infants $>18$ hours), maternal fever during labor, intra-amniotic infection, and chorioamnionitis. Two or more abnormal values of the sepsis screen (white blood cell count 10.000/ $\mathrm{mm} 3$, immature-to-total neutrophil ratio higher than 0.2 and positive C-reactive protein (CRP)) were considered as supportive for diagnosis of infection) Johnson et al., 1997).

Infants were excluded if they had congenital malformations, congenital infections associated with the TORCH complex, and refusal of parental consent. The following routine laboratory assessments of sepsis were done for all participants included blood culture, complete blood count (CBC), total and differential white cell count, platelet count and CRP.

\section{Blood sampling}

Venous blood samples were aseptically collected in sterile plain and EDTA tubes, centrifuged at $3000 \mathrm{rpm}$ for $10 \mathrm{~min}$ at $4^{\circ} \mathrm{C}$ to obtain serum and plasma which were stored at $-20^{\circ} \mathrm{C}$ till analysis.

First blood samples were obtained from patients at day 0 immediately at the time of sepsis diagnosis during first 72 hours after birth. Another sample was obtained from each patient at day 5 after antibiotic therapy. Only one blood sample was obtained from each healthy control subject.

\section{Biochemical assessments}

The serum HMGB1 and Hsp72 as well as plasma thrombomodulin concentrations were measured using enzyme-linked immunosorbent assay (ELISA) kits (Sunred
Company, City, State, USA; Chongqing Biospes Co., Ltd, City, China; R\&D Systems, City, State, USA respectively). All ELISA techniques were done according to the manufacturer's protocol and read on microplate reader (Stat Fax®2100, Fisher Bioblock Scientific, France), at $450 \mathrm{~nm}$ with correction wavelength set at $570 \mathrm{~nm}$. In addition serum nitric oxide (NO) and hydrogen peroxide $\left(\mathrm{H}_{2} \mathrm{O}_{2}\right)$ concentrations were assessed in serum using commercial kits supplied by Biodiagnostic Company, Egypt.

\section{Statistical analysis}

Analysis was performed by Statistical Package for Social Sciences, version 14.0 for windows (SPSS, Chicago, IL, USA). Data were expressed as mean + standard deviation.

Paired and unpaired t-test for comparison between means of two groups and one way analysis of variance (ANOVA) for comparison between means of three groups were used. The level of significance was set at $\mathrm{p}<0.05$. Receiver operating characteristics (ROC) analysis was used to identify the optimal diagnostic values of the studied parameters.

\section{Results and Discussion}

Demographic data, clinical characteristics and routine laboratory data of the studied neonates

Table 1 shows that there were non-significant differences between group 1 and 2 regarding gestational age, birth weight, hemoglobin level, polymorph nuclear leucocytic count (PMN) and total leucocytic count (TLC) (p $>0.05$ ) moreover, platelet count showed a significant decrease in group 1 when compared with group 2 ( $\mathrm{p}<0.05)$. CRP showed significant increase in group 1 when compared to group 2 ( $\mathrm{p}<0.05)$. 


\section{Blood culture results}

Table 2 shows the blood culture results of those 19 infants with culture positive results.

\section{Inflammatory biomarkers associated sepsis}

Table 3 shows a significant increase in HMGB1serum level in sepsis group patients (group 1 at 0 day and 5 days after antibiotic therapy) when compared to group 2. Meanwhile, Hsp72 and thrombomodulin showed a significant decrease in sepsis group patients (group 1 at 0 day and 5 days after antibiotic therapy) when compared to group 2 $(\mathrm{P}<0.05)$.There was a significant decrease in HMGB1 in group 1 at day 5 after antibiotic therapy when compared to the same group at day 0 while $\mathrm{Hsp} 72$ and thrombomodulin showed the reverse $(\mathrm{P}<0.05)$.

Table 4 shows that HMGB1 concentrations at day 0 were significantly higher in group 1a compared to group $1 \mathrm{~b}(\mathrm{P}<0.05)$ with a nonsignificant decrease at day $5(\mathrm{P}>0.05)$, also there was a significant decrease in HMGB1 in group 1a at day 5 compared to day 0 levels $(\mathrm{P}<0.05)$, moreover, similar finding was not found in group $1 \mathrm{~b}(\mathrm{P}>0.05)$.

Plasma thrombomodulin level was significantly lower in group 1a compared to group $1 \mathrm{~b}$ at day $0(\mathrm{P}<0.05)$ however, it showed a non-significant difference between groups $1 \mathrm{a}$ and $1 \mathrm{~b}$ at day 5 after antibiotic therapy $(\mathrm{P}>0.05)$, moreover, thrombomodulin level was significantly increased in groups 1a and $1 \mathrm{~b}$ after antibiotic therapy compared to day 0 concentrations $(\mathrm{P}<0.05)$. Serum Hsp72 levels showed non-significant different between group $1 \mathrm{a}$ and group $1 \mathrm{~b}$ at days 0 and 5 (P> 0.05), however, they significantly increased after antibiotic therapy in both group 1a and group $1 \mathrm{~b}$ compared to their levels prior to antibiotic therapy $(\mathrm{P}>0.05)$. In table $4 \mathrm{CRP}$ concentrations were non-significantly higher in group 1a compared to group $1 \mathrm{~b}$ at day 0 and at day 5 after antibiotic treatment $(\mathrm{P}>0.05)$, moreover, CRP significantly decreased after antibiotic therapy in both group 1a and group $1 \mathrm{~b}$ compared to their concentrations prior to antibiotic therapy compared to day 0 concentrations $(\mathrm{P}<0.05)$.

\section{Results of redox status biomarkers}

Table 3 shows a significant increase of both $\mathrm{NO}$ and $\mathrm{H}_{2} \mathrm{O}_{2}$ serum levels in group 1 at 0 day and 5 days after antibiotic therapy when compared to group $2(\mathrm{P}<0.05)$. In addition, $\mathrm{NO}$ and $\mathrm{H}_{2} \mathrm{O}_{2}$ showed a significant decrease in group 1 at day 5 when compared to the same group at day $0(\mathrm{P}<0.05)$. In table 4 serum NO and $\mathrm{H}_{2} \mathrm{O}_{2}$ were significantly higher in group 1 a compared to group $1 \mathrm{~b}$ at day $0(\mathrm{P}<0.05)$, however, there was a non-significant difference between groups $1 \mathrm{a}$ and $1 \mathrm{~b}$ at day 5 after antibiotic therapy $(\mathrm{P}>0.05)$.

Moreover, after antibiotic therapy serum NO and $\mathrm{H}_{2} \mathrm{O}_{2}$ levels showed significant decrease in groups $1 \mathrm{a}$ and $1 \mathrm{~b}(\mathrm{P}<0.05)$.

\section{Results obtained from ROC curve}

Table 5 summarizes the results obtained from ROC curve analysis for diagnostic values of all studied biomarkers.

Blood culture is the gold standard for the diagnosis of sepsis, but at least 48-72 hours are needed for the results and the number of false negative results is not negligible, particularly in early-onset sepsis) Hisamuddin et al., 2015). In the last decades, a great deal of efforts has been focused on biochemical markers for early diagnosis of sepsis and link those biomarkers to the results of blood culture. CRP has been considered as a biomarker for sepsis for many years, but it is considered as a non-specific biomarker) Hisamuddin et al., 2015). 
Table.1 Comparison between the studied groups regarding descriptive data

\begin{tabular}{|c|c|c|}
\hline Groups/Parameters & $\begin{array}{c}\text { Group } 1 \text { (sepsis group } \\
\qquad \mathbf{n = 3 0} \text { ) }\end{array}$ & $\begin{array}{c}\text { Group } 2 \text { (control group } \\
\qquad \mathbf{n = 1 5 )}\end{array}$ \\
\hline Gestational age (weeks) & $36.9 \pm 1.8$ & $37.1 \pm 1.1$ \\
\hline Birth weight (gm) & $3040 \pm 269$ & $3192 \pm 135$ \\
\hline $\begin{array}{l}\text { Mode of delivery, } \\
\text { Cesarean delivery, } n(\%)\end{array}$ & $14(47 \%)$ & $10(67 \%)$ \\
\hline Chorioamnionitis, n (\%) & $20(67 \%)$ & $3(20 \%)$ \\
\hline $\begin{array}{l}\text { Premature rupture of } \\
\text { membrane, } n(\%)\end{array}$ & $18(60 \%)$ & $2(13 \%)$ \\
\hline $\begin{array}{l}\text { Mechanical ventilation, } \mathbf{n} \\
(\%)\end{array}$ & $10(33 \%)$ & - \\
\hline $\begin{array}{l}\text { Disseminated } \\
\text { intravascular coagulation }\end{array}$ & $12(40 \%)$ & - \\
\hline $\begin{array}{l}\text { Apgar score (first } \\
\text { minute) (range/median) }\end{array}$ & $4-8(4.5)$ & $5-8(6)$ \\
\hline $\mathrm{Hb}(\mathrm{g} / \mathrm{dl})$ & $13.5 \pm 1.9$ & $14.1 \pm 1.1$ \\
\hline TLC $\left(x 10^{3} / \mathrm{uL}\right)$ & $12.1 \pm 3.1$ & $11.4 \pm 5.2$ \\
\hline PMN count $\left(x 10^{3} / \mathrm{uL}\right)$ & $5.9 \pm 3.1$ & $5.7 \pm 2.9$ \\
\hline Platelet count $\left(\mathrm{x} 10^{3} / \mathrm{uL}\right)$ & $161 \pm 82 *$ & $301 \pm 48$ \\
\hline CRP (mg/L) & $22.1 \pm 6.2 *$ & $4.2 \pm 1.5$ \\
\hline
\end{tabular}

Data are mean \pm standard deviation of each group except range and median for Apgar score. Student t- test was used to compare significance between the groups. *Significant at p value $<0.05$. Hb; Hemoglobin, TLC; Total leucocytic count, PMN; polymorph nuclear leucocytic, CRP; $\mathrm{C}$ reactive proteins.

Table. 2 Bacterial isolates ratio in patients with culture-proven sepsis (group 1a) $(n=19)$

\begin{tabular}{|c|}
\hline $\begin{array}{c}\text { culture proven sepsis (group Ia) } \mathbf{n} \\
\text { and } \%\end{array}$ \\
\hline Coagulase-negative staphylococci \\
\hline Escherichia coli \\
\hline Staphylococcus aureus \\
\hline Pseudomonas aeruginosa \\
\hline Streptococcus viridans \\
\hline Klebsiella pneumoniae
\end{tabular}

\begin{tabular}{|c|}
\hline $19(63.33 \%)$ \\
\hline $6(31.58 \%)$ \\
\hline $5(26.32 \%)$ \\
\hline $3(15.78 \%)$ \\
\hline $2(10.53 \%)$ \\
\hline $2(10.53 \%)$ \\
\hline $1(5.26 \%)$ \\
\hline
\end{tabular}


Table.3 Comparison between the studied groups regarding inflammatory Biomarkers and redox status

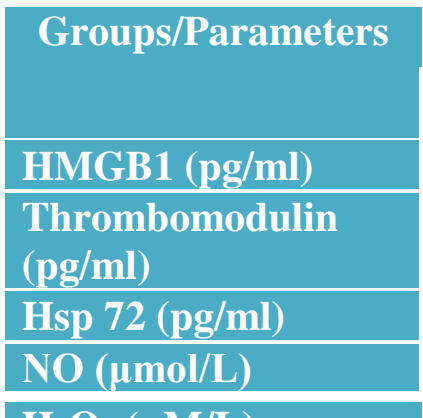

\begin{tabular}{|l|}
\hline A \\
\hline 65 \\
\hline 72.3 \\
\hline 1 \\
\hline 3 \\
\hline
\end{tabular}

Group 1 (sepsis group $n=30$ )

At day $0^{\text {a }}$

$65.7 \pm 8.7^{\mathrm{bc}}$

$72.3 \pm 11.2^{\mathrm{bc}}$

$14.6 \pm 1.6^{\mathrm{bc}}$

$33.4 \pm 9.1^{\mathrm{bc}}$

$59.6 \pm 7.9^{\mathrm{BC}}$
At day $\mathbf{5}^{\text {b }}$

$54.8 \pm 5.8^{\text {ac }}$

$94.3 \pm 7.6^{\mathrm{ac}}$

$21.5 \pm 2.7^{\text {ac }}$

$17.7 \pm 2.4^{\mathrm{ac}}$

48.6 $\pm 4.9^{\mathrm{ac}}$
Group 2 (control

group $n=15)^{c}$

\begin{tabular}{|c|}
\hline $38.2 \pm 9.9^{a \mathrm{ab}}$ \\
\hline $144.2 \pm 15.6^{\mathrm{ab}}$ \\
\hline $32.6 \pm 4.3^{\mathrm{ab}}$ \\
\hline $13.6 \pm 1.8^{\mathrm{ab}}$ \\
\hline $35.0 \pm 3.4^{\mathrm{ab}}$
\end{tabular}

Data are mean \pm standard deviation of each group. One-way ANOVA with Tukey's post hoc test were used to compare significance between groups. *Significant at $\mathrm{p}$ value $<0.05$. HMGB1; high mobility group box 1 , Hsp 72 ; heat shock protein $72, \mathrm{NO}$; Nitric oxide, $\mathrm{H}_{2} \mathrm{O}_{2}$; hydrogen peroxide, CRP. ${ }^{\text {ab, }, \mathrm{c}}$ significance between groups, ${ }^{\text {a }}$ significance from group 1 at day $0,{ }^{b}$ significance from group 1 at day $5,{ }^{c}$ significance from group 2 .

Table.4 Comparison between studied biomarkers in groups 1a and $1 \mathrm{~b}$ before and 5 days after antibiotic therapy

\begin{tabular}{|c|c|c|c|c|}
\hline \multicolumn{1}{|c|}{ Parameter } & & $\begin{array}{c}\text { Group 1a } \\
\mathbf{n = 1 9}\end{array}$ & $\begin{array}{c}\text { Group 1b } \\
\mathbf{n = 1 1}\end{array}$ & $\begin{array}{c}\text { unpaired t test } \\
\text { p }\end{array}$ \\
\hline \multirow{2}{*}{ HMGB1 $(\mathbf{p g} / \mathbf{m l})$} & Before & $70.4 \pm 6.4$ & $57.5 \pm 5.6$ & $0.001 *$ \\
\hline & After & $54.1 \pm 6.9$ & $55.6 \pm 2.9$ & 0.9 \\
\hline Paired t-test & p & $0.001 *$ & 0.8 & \\
\hline Thrombomodulin $(\mathbf{p g} / \mathbf{m l})$ & Before & $67.8 \pm 10.7$ & $80.1 \pm 7.4$ & $0.002 *$ \\
& After & $92.6 \pm 6.4$ & $97.2 \pm 8.9$ & 0.4 \\
\hline Paired t-test & p & $0.002 *$ & $0.03 *$ & \\
\hline Hsps 72 $(\mathbf{p g} / \mathbf{m l})$ & Before & $14.6 \pm 1.5$ & $14.6 \pm 1.9$ & 0.9 \\
\hline & After & $21.6 \pm 3.2$ & $21.9 \pm 1.7$ & 0.5 \\
\hline Paired t-test & p & $0.002 *$ & $0.001 *$ & \\
\hline NO $(\boldsymbol{\mu m o l} / \mathbf{L})$ & Before & $36.4 \pm 8.8$ & $28.1 \pm 7.3$ & $0.01 *$ \\
\hline Paired t-test & After & $17.9 \pm 2.0$ & $17.5 \pm 3.1$ & 0.6 \\
\hline $\mathbf{H}_{\mathbf{2}} \mathbf{O}_{\mathbf{2}}(\boldsymbol{\mu m o l} / \mathbf{L})$ & p & $0.001 *$ & $0.001 *$ & \\
\hline \multirow{2}{*}{ Paired t-test } & Before & $61.3 \pm 7.4$ & $55.3 \pm 7.0$ & $0.04 *$ \\
\hline CRP(mg/L) & After & $46.3 \pm 4.3$ & $47.0 \pm 5.5$ & 0.7 \\
\hline Paired t-test & p & $0.001 *$ & $0.001 *$ & \\
\hline & Before & $22.2 \pm 7.4$ & $21.9 \pm 3.6$ & 0.07 \\
\hline & After & $7.0 \pm 1.3$ & $6.3 \pm 1.6$ & 0.23 \\
\hline
\end{tabular}

Data are mean \pm standard deviation of each group. To compare significance between the two groups paired and unpaired t-test were used. *Significant at p value < 0.05 . HMGB 1; high mobility group box 1, Hsp 72; heat shock protein 72, NO; Nitric oxide, $\mathrm{H}_{2} \mathrm{O}_{2}$; hydrogen peroxide; CRP; $\mathrm{C}$ reactive protein. 
Table.5 Diagnostic value of the inflammatory mediators and redox status

\begin{tabular}{|c|c|c|c|c|c|}
\hline Parameter & $\begin{array}{l}\text { Cut-off } \\
\text { value }\end{array}$ & $\begin{array}{c}\text { Sensitivity } \\
(\%)\end{array}$ & $\begin{array}{c}\text { Specificity } \\
(\%)\end{array}$ & $\begin{array}{l}\text { Area under } \\
\text { the curve }\end{array}$ & P value \\
\hline HMGB1 (pg/ml) & $>49.5$ & 97 & 94 & 0.99 & $0.001 *$ \\
\hline CRP (mg/L) & $>15.5$ & 96 & 93 & 0.98 & $0.001 *$ \\
\hline $\mathrm{H}_{2} \mathrm{O}_{2}(\mu \mathrm{M} / \mathrm{L})$ & $>46.5$ & 96 & 67 & 0.93 & $0.001 *$ \\
\hline $\begin{array}{c}\text { Thrombomodulin } \\
(\mathrm{pg} / \mathrm{ml})\end{array}$ & $>63.5$ & 87 & 99 & 0.92 & $0.001 *$ \\
\hline $\mathrm{NO}(\mu \mathrm{mol} / \mathrm{L})$ & $>20.5$ & 96 & 89 & 0.90 & $0.001 \%$ \\
\hline Hsp 72 (pg/ml) & $>17$ & 90 & 80 & 0.21 & $0.001 *$ \\
\hline
\end{tabular}

HMGB1; high mobility group box 1 , Hsp 72; heat shock protein 72 , NO; Nitric oxide, $\mathrm{H}_{2} \mathrm{O}_{2}$; hydrogen peroxide, $\mathrm{CRP} ; \mathrm{C}$ reactive protein.

Recent evidence indicates that HMGB1, a ubiquitous nuclear protein, is an important pro-inflammatory cytokine that mediates the response to infection, injury, and inflammation, although residing predominantly in the nucleus of quiescent macophages/monocytes (Vande Walle et al., 2011), results of current study revealed a significant increase of HMGB 1 in sepsis group when compared to healthy control group moreover there was a significant decrease of HMGB1 at day 5 after antibiotic therapy only in group 1a patients that explained its important role in the diagnosis and treatment of sepsis. Moreover, HMGB1 showed a significant increase in group 1a when compared to group $1 \mathrm{~b}$ that reflected its correlation with blood culture results and established it as an important target for sepsis diagnostic and therapy (Buhimschi et al., 2009).

HSPs are highly-conserved and present in cells under normal conditions, but are overexpressed under some specific stress conditions such as sepsis (Tsai et al., 2015) moreover, Hsp72 over-expression can reduce mortality in experimental models of septic shock and can down-regulate expression of inflammatory genes (Struzik et al., 2015). Results of the current study revealed a significant decrease of Hsp72 in group 1 when compared to group 2 moreover, there was a significant increase of Hsp72 at day 5 after antibiotic therapy reflect its role in the diagnosis and treatment response of sepsis. Moreover, culture positive and culture negative groups showed a non-significant difference as regard to Hsp72 level that made it as un-suitable biomarker for blood culture results.

Nuclear factor kappa B (NF- $\mathrm{B})$ signaling pathways regulate the transcription of many genes involved in immunity and inflammation one of them is HMGB1.

Hsp72 modulatory effects on inflammation can be attributed to its regulation of the $N F \kappa B$ pathway by its potent inhibitory effects on HMGB1-induced activation of NF- $\kappa$ B pathways (Song et al., 2008), these findings identify an essential role for HSP72 in blocking inflammation and preventing HMGB1 release, making them cornerstones for better understanding and management of neonatal sepsis and greatly support the aim of our results and giving a new promising hope for better therapeutic approaches of neonatal sepsis.

The activated NFאB pathway leads to the production of ROS that cause tissue damage during sepsis (Marshall and Reinhart, 2009). 
Results revealed that both $\mathrm{NO}$ and $\mathrm{H}_{2} \mathrm{O}_{2}$ showed a significant increase in sepsis group when compared to control groups in addition, there was a significant decrease of both biomarkers at day 5 after antibiotic therapy that highlighted their role in sepsis diagnosis and treatment.

In addition, both $\mathrm{NO}$ and $\mathrm{H}_{2} \mathrm{O}_{2}$ correlate positively with blood culture results as it showed a significant increase in group 1a when compared to group $1 \mathrm{~b}$ that reflect their importance as blood culture related biomarker for early onset neonatal sepsis. Valerio et al., 2012 who did a study on neonatal sepsis reported that sepsis promotes production of an excess of ROS and these molecules are meant to destroy the infectious agent but are not specific substances and may instead harm the patient. Meanwhile, Sirisinha (2011) reported that induction of Hsp72 can suppress lipopolysaccharide-induced HMGB1 release as well as inhibition of oxidative stressinduced HMGB1 release by direct protein-toprotein interaction in macrophages, this support greatly the beneficial effect of targeting the aforementioned studied biomarkers in the therapy of neonatal sepsis. At physiological conditions, the anticoagulant system comprising antithrombin (AT), thrombomodulin/activated protein $\mathrm{C}$ (APC), and tissue factor pathway inhibitor (TFPI) is activated in response to hypercoagulability; however, this anticoagulant system is severely compromised in individuals with sepsis (Okamoto et al., 2012). Results of the current study revealed a significant decrease of thrombomodulin in group 1 when compared to group 2 moreover; there was a significant increase of it at day 5 after antibiotic therapy reflects its role in the diagnosis and treatment response of sepsis. In addition, thrombomodulin showed a significant decrease in group 1a when compared to group $1 \mathrm{~b}$ that reflect its role as suitable blood culture related biomarker for early onset neonatal sepsis. These results run hand in hand with the results of Hao and Wang 2013 who reported that determination of thrombomodulin levels may be helpful in evaluating severity, prognosis and drug response in neonates with early onset sepsis. Well, in line another mechanism for thrombomodulin in sepsis is its effect on HMGB1. During inflammation HMGB1 is released and bind to the receptor for advanced glycation end products (RAGE), HMGB1RAGE signaling has been implicated in the pathogenesis and/or progression of sepsis, thrombomodulin interferes with HMGB1 binding to RAGE, thereby impairing HMGB1-RAGE signaling, alternatively, thrombomodulin may antagonize HMGB1 by enhancing thrombin-mediated proteolytic degradation of it to less a pro-inflammatory form (Kashiwadate et al., 2016), that confirms their patho-physiological mechanism in neonatal sepsis making them promising candidates for therapy that may help in reducing the period and the dose of antibiotic treatment of sepsis to reduce patient suffering. Diagnostic values obtained from the ROC curve showed that HMGB1 had the best accuracy, followed by CRP which is a nonspecific biomarker for sepsis diagnosis. To our knowledge, the combination between current studied biomarkers together in the pathogenesis of early onset neonatal sepsis has not been studied before. HMGB1, thrombomodulin, Hsp72 and redox status as an intricate biomarkerS network can be used for diagnosis and treatment response of early onset neonatal sepsis, which makes them as promising targets for diagnosis, management and treatment of early onset neonatal sepsis.

\section{Authors' contributions}

This work was carried out in collaboration between all authors. Author NAS reached literature and conceived the study, contributed 
to biochemical performed data analysis and wrote the first draft of the paper. Author MSF was involved in protocol development, gaining ethical approval, patient recruitment and data analysis. Author WHA as involved in protocol development, gaining ethical approval and tissue culture assy. All authors reviewed, edited the manuscript and approved the final manuscript.

\section{Acknowledgement}

The authors would like to express their deepest thanks to all participants included in this study.

\section{Competing of interest}

Authors have declared that no competing interests exist.

\section{References}

Buhimschi CS' Baumbusch MA, Dulay AT, et al., Characterization of RAGE, HMGB1, and S100beta in inflammation-induced preterm birth and fetal tissue injury. Am J Pathol 2009; 175(3):958-975. doi: 10.2353/ajpath. 2009.090156. Epub 2009 Aug 13.

Camacho-Gonzalez A, Spearman PW, Stoll BJ. Neonatal infectious diseases: evaluation of neonatal sepsis. Pediatr Clin North Am 2013; 60:367-89. doi: 10.1016/j.pcl.2012.12.003.

Evans CG, Chang L, Gestwicki JE. Heat shock protein 70 (hsp70) as an emerging drug target. J Med Chem 2010; 53: 4585-4602.

Hao L, Wang N. [Changes in plasma thrombomodulin and D-dimer levels and their clinical significance in neonates with sepsis]. Zhongguo Dang Dai Er Ke Za Zhi. 2013; 15(10):841844.

Hisamuddin E, Hisam A, Wahid S, et al. Validity of C-reactive protein (CRP) for diagnosis of neonatal sepsis. Pak J Med
Sci 2015; 31(3):527-531. doi: 10.12669/pjms.313.6668.

Hofer N, Zacharias E, Müller W, et al., An update on the use of C-reactive protein in early-onset neonatal sepsis: current insights and new tasks. Neonatology 2012; 102: 25-36. doi: 10.1159/ 000336629.

Huang LF, Yao YM, Sheng ZY. Novel insights for high mobility group box 1 protein-mediated cellular immune response in sepsis: A systemic review. World J Emerg Med 2012; 3(3):165171. doi: 10.5847/wjem.j.19208642.2012.03.001.

Johnson CE, Whitwell JK, Pethe $\mathrm{K}$, et al., Term newborns who are at risk for sepsis: are lumbar punctures necessary? Pediatrics 1997; 99(4):E10.

Kashiwadate $\mathrm{T}$, Miyagi S, Hara $\mathrm{Y}$, et al., Soluble Thrombomodulin Ameliorates Ischemia-Reperfusion Injury of Liver Grafts by Modulating the Proinflammatory Role of High-Mobility Group Box 1. Tohoku J Exp Med 2016; 239(4):315-323. doi: 10.1620/tjem.239. 315.

Klinger G, Levy I, Sirota L, et al., Neonatal Network. Outcome of early-onset sepsis in a national cohort of very low birth weight infants. Pediatrics 2010; 125: 736-740. doi: 10.1542/peds.2009-2017.

Marshall JC, Reinhart K. International Sepsis Forum. Biomarkers of sepsis. Crit Care Med 2009; 37(7): 2290-2298.

Okamoto K, Tamura T, Sawatsubashi Y. Sepsis and disseminated intravascular coagulation. J Intensive Care 2016; 4:23-30. doi: 10.1186/s40560-0160149-0.

Okamoto T, Tanigami H, Suzuki K, et al., Thrombomodulin: a bifunctional modulator of inflammation and coagulation in sepsis. Crit Care Res Pract 2012; 2012:1-10. doi: $10.1155 / 2012 / 614545$. 
Palazzi DB, Klein JO, Baker CJ. Bacterial sepsis and meningitis. In: Remington JS, Klein JO, Wilson CB, Baker CJ, editors. Infectious Diseases of the Fetus and Newborn Infant. 6th ed. Philadelphia: Elsevier Saunders 2006; 247-295.

Pisetsky DS, Gauley J, Ullal AJ. HMGB1 and microparticles as mediators of the immune response to cell death. Antioxid Redox Signal 2011; 15:2209-2219.

Saugstad OD. Oxidative stress in the newborn-a 30-year perspective. Biol Neonate. 2005; 88(3):228-36.

Sirisinha S. Insight into the mechanisms regulating immune homeostasis in health and disease. Asian Pac J Allergy Immunol 2011; 29(1):1-14.

Song M, Pinsky MR, Kellum JA. Heat shock factor 1 inhibits nuclear factor-kappaB nuclear binding activity during endotoxin tolerance and heat shock. J
Crit Care 2008; 23(3):406-15. doi: 10.1016/j.jcrc.2007.09.007.

Struzik J, Szulc-Dąbrowska L, Niemiałtowski M. [Participation of heat shock proteins in modulation of NF-кB transcription factor activation during bacterial infections]. Postepy Hig Med Dosw 2015; 69:969-977. doi: 10.5604/17322 693.

Tsai TN, Lee TY, Liu MS, et al., Release of endogenous heat shock protein 72 on the survival of sepsis in rats. J Surg Res. 2015; 198(1):165-74. doi: 10.1016/j.jss. 2015.05.004.

Valerio TA, Cancelier AC, Constantino L, et al., Inflammatory and oxidative cord blood parameters as predictors of neonatal sepsis severity. Rev Bras Ter Intensiva 2012; 24(1):30-34.

Vande Walle L, Kanneganti TD, Lamkanfi M. HMGB1 release by inflammasomes. Virulence 2011; 2:162-165.

\section{How to cite this article:}

Nema A. Soliman, Mohamed S. El Farargy and Wesam H. Amer. 2018. Interplay between Inflammation, Coagulation And Redox Status in Early Onset Neonatal Sepsis: Insight into Prediction, Diagnosis and Management. Int.J.Curr.Microbiol.App.Sci. 7(03): 1073-1082. doi: https://doi.org/10.20546/ijcmas.2018.703.128 